\title{
Comparison of two incremental protocols for evaluation of hip extension
}

\section{Comparação de dois protocolos progressivos na avaliação da extensão de quadril}

\section{Christian Campos Jara ${ }^{[a]}$, Luis Javier Chirosa Ríos ${ }^{[b]}$, Daniel Jerez Mayorga ${ }^{[\mathrm{c}]}$, Ignacio Chirosa Rios ${ }^{[\mathrm{b}]}$, Cristian Martínez Salazar ${ }^{[\mathrm{d}]}$, Pedro Cesar Beraldo ${ }^{[\mathrm{e}]^{*}}$}

[a] Universidad Andrés Bello, Santiago, Santiago, Chile

[b] Universidad de Granada (UGR), Granada, Andalucía, Spain

[c] Universidad San Sebastián, Santiago, Santiago, Chile

[d] Universidad de La Frontera (UFRO), Temuco, La Araucanía, Chile

[e] Pontifícia Universidade Católica do Paraná (PUCPR), Curitiba, PR, Brazil

\section{Abstract}

Introduction: The hip muscles play an important role in controlling the transverse and frontal plane of the femur during displacement. The hip extension and abduction/adduction exercises are among the most widely evaluated protocols both clinically and in research. Objective: To compare which assessment protocol in an isokinetic strength regime (distal grip-ankle vs. proximal grip-knee) best represents the action of hip extension and to analyze the test-retest reliability in the variables peak force (PF) and work (W). Methods: A total of 20 subjects participated in this research. All participants were female. The mean and standard deviations of age, weight and height were $21 \pm 3.9$ years, $65 \pm 11 \mathrm{~kg}, 166 \pm 3.4 \mathrm{~cm}$, respectively. Results: Significant differences were found in both variables (PF and W) between protocols 1 and 2 ( $\mathrm{p}<$ $0.05)$ on assessment days 1 and 2 . No differences between days 1 and day 2 in either protocol $(\mathrm{p}<0.05)$ were found. Index values of interclass correlation (ICC) of protocol 1 ranged between 0.38 and 0.86 . In protocol 2 the ICC range was between 0.33 and 0.87 . Conclusions: In light of these results, the hip extension exercise with a proximal grip best represents the strength of the muscle groups involved in this action.

Keywords: Hip. Muscle Strength. Lower Extremity. Strength Training.

* CCJ: PhD, e-mail: christian.campos.jara@gmail.com LJCR: MS, e-mail: lchirosa@ugr.es

DJM: MS, e-mail: djerezmayorga@gmail.com

ICR: PhD, e-mail: ichirosa@ugr.es

CMS: MS, e-mail: cristian.martinez.s@ufrontera.cl

PCB: MS, e-mail: p.beraldo@pucpr.br 


\section{Resumo}

Introdução: Os músculos do quadril desempenham um papel importante no controle do plano transverso e frontal do fêmur durante o deslocamento. Os exercícios de extensão e abdução/adução do quadril estão entre os protocolos mais amplamente avaliados tanto na clínica como na pesquisa. Objetivo: Comparar qual protocolo de avaliação em um regime de força isocinética (aperto distal no tornozelo versus aperto proximal no joelho) melhor representa a ação de extensão de quadril e analisar a confiabilidade teste-reteste nas variáveis de força máxima de (FM) e trabalho (T). Métodos: Um total de 20 indivíduos participou desta pesquisa. Todos os participantes eram do sexo feminino. A média e desvios-padrão de idade, peso e altura foram $21 \pm 3.9$ anos, $65 \pm$ $11 \mathrm{~kg}$ e $166 \pm 3.4 \mathrm{~cm}$, respectivamente. Resultados: Foram encontradas diferenças significativas em ambas as variáveis (FM e T) entre protocolos 1 e $2(p<0,05)$ nos dias 1 e 2 de avaliação. Não houve diferenças entre os dias 1 e dia 2 em qualquer protocolo $(p<0,05)$. O índice de valores de correlação interclasse (ICC) do protocolo 1 variou entre 0,38 e 0.86. No protocolo 2 a faixa do ICC foi entre 0,33 e 0,87. Conclusões: Tendo em conta estes resultados, o exercício de extensão de quadril com uma fixação proximal é quem melhor representa a força dos grupos musculares envolvidos nesta ação.

Palavras-chave: Quadril. Força Muscular. Extremidade Inferior. Treinamento de Resistência.

\section{Introduction}

The hip muscles play an important role in controlling the transverse and frontal plane of the femur during displacement $(1,2)$. Hip extension and abduction/ adduction exercises are among the most widely evaluated research and clinical protocols $(3,4)$. Typically, when these exercises are carried out isokinetically, the values of peak force (PF), work (W) and power (P) of the lower body are most commonly used (5-10). Therefore, one of the main functions of the isokinetic assessment of hip musculature is to determine the values of $\mathrm{PF}$, and $\mathrm{W}$ to prevent falls and restore balance to unstable situations $(6,11)$. In addition, weakness and strength imbalances of the gluteus maximus (GM) are associated with lower limb injuries, including patellofemoral pain syndrome, ACL tears, and chronic ankle instabilities (12 - 15). Weakness in the GM muscles also leads to poor posture, difficulty walking and requires support from synergist muscles, thus causing other functional imbalances. Therefore, a specific GM neuromuscular re-education to strengthen these muscles is clinically recommended in rehabilitation programs to prevent or reduce lower back pain and to prevent lower body injuries (16). On the other hand, evaluations of these exercises should be necessary because a lack of reliability in the measurements can have negative consequences on the decision-making process in both diagnosis and design of specific treatments.

Normally, the hip extension exercise is measured starting from a supine or prone position, using a range of motion (ROM) of 90 degrees. Further, straps are frequently used to immobilize and secure the trunk to the support bench of isokinetic device itself $(5,17,18)$. However, this creates an overly analytic situation that does not represent the functional reality of this set of muscles. Therefore, the use of mathematical models designed to predict the force generated in these movements is recommended (19-21). The strength of the hip muscles has been studied in order to correlate its value with functional imbalances that can lead to lower body injury. Hollman et al. (11), analyzed hip strength through isometric actions in abduction and adduction, as well as internal and external rotation. Correlations between force values versus the $Q$ angle of knee and foot arch were ( $r=0.35, p=0.025)$. Kollock et al. (9) compared different exercises involving the major hip muscles to determine if an isometric measure could replace an isokinetic measurement. The results supported the idea of replacing one isometric value for an isokinetic value and highlighted the substantial cost and limited portability of isokinetic systems as compared to devices that are easier to use.

The term reliability refers to the stability of a measure over the course of multiple measurements (7). Generally, in health sciences reliability is confirmed using the test-retest method (22). Based on this, if a measurement of an individual is tested for a dependent variable on multiple occasions, the higher rate of intraclass correlation (ICC) obtained, the more reliable the measure. Furthermore, if the values of standard error of measurement (SEM) are known, both partial reliability as well as absolute reliability of these variables is known. Boling et al. (17) conducted 
a hip extension work comparison protocol in patients with and without patello-femoral pain. The ICC and SEM of hip extension for variable PF were 0.79 and $15.63 \mathrm{~N}$, and 0.89 and $15.01 \mathrm{~N}$ for concentric and eccentric phases, respectively. On the other hand, Burnett et al. (23) analyzed the reliability of torque produced by an isokinetic hip extension exercise in children. The speeds tested were $30^{\circ} \mathrm{x} \mathrm{sec}^{-1}$ and 90 ${ }^{\circ} \mathrm{x} \mathrm{sec}{ }^{-1}$ on two different days. The ICC obtained for flexion and hip extension at $30^{\circ} \mathrm{x} \mathrm{sec}^{-1}$ and $90^{\circ} \mathrm{x}$ sec $^{-1}$ were $0.63,0.75$ and $0.68,0.84$, respectively. The authors concluded that there are many factors that influence the reliability test, such as lack of precision in body placement at the start and end of ROM, and evaluation by the same evaluator. These are some of most important factors to consider.

Therefore, due to the lack of research evaluating the strength of hip extension in a functional status, the objectives of this study were to (a) analyze which assessment protocol on an isokinetic device (distal grip-ankle vs. proximal grip-knee) best represents the action of hip extension and (b) to analyze the testretest reliability for the variables peak force and work.

\section{Methods}

\section{Participants}

A total of 20 female participants carried out this research. The mean and standard deviation of age, weight and height were $21 \pm 3.9$ years, $65 \pm 11 \mathrm{~kg}, 166 \pm 3.4$ $\mathrm{cm}$. Prior to the assessment tests all participants signed an informed consent explaining the risks and benefits of participation in this research. The Ethics Committee at the University of Granada approved the procedure and the research was conducted in accordance with the Declaration of Helsinki (1964).

\section{Procedure}

All tests were performed in a physical therapy clinic (Fisiosalud, Peligros, Granada, Spain). The procedure was explained to each of the participants in advance of the isokinetic evaluation test. All volunteers participated in two familiarization sessions prior to the testing. No participant had prior experience in conducting isokinetic tests. Participants performed a standardized warm-up consisting of 5 minutes on a stationary bike plus 2 sets of 15 repetitions of a specific movement rate (i.e. hip extension at a rate of $0.50 \mathrm{~m} \mathrm{x} \mathrm{sec}^{-1}$ ). After the warm-up was completed all the participants had a 5-minute break for rest and hydration.

Hip Extension Test (HET) on the Haefni Health System $1.0(\mathrm{HHe} 1.0)$

All participants were instructed to perform the hip extension exercise under the same mechanical conditions. They were positioned in an anatomical position standing in front of the HHe1.0 device. The pulley height was adjusted so that the resistance vector was perpendicular to the column with the mobile arm moved by the pulleys. In the initial position (Figure 1), the feet were spread hip width apart, facing the pulley arm, this being the bisector relative to inside of the ankle (medial malleolus). To compare both assessment situations (distal grip-ankle vs. proximal grip-knee) a ROM of $30 \mathrm{~cm}$ was previously established for all participants. During the evaluation, the body was upright. Participants kept their arms by their sides with their hands resting on a support to maintain balance during the test. The same researcher responsible for putting the participants in the correct evaluation position performed all evaluations.

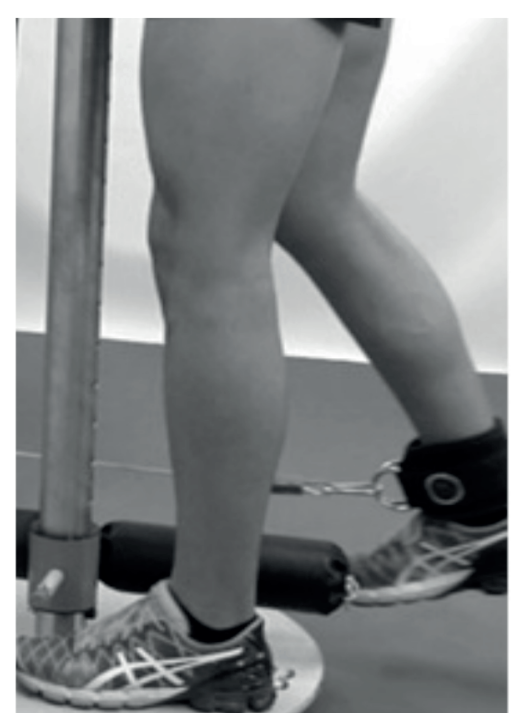

Figure 1 - Initial position.

Each exercise consisted of a hip extension with the support leg fully extended and the moving leg slightly bent to an angle of no more than $30^{\circ}$. Each participant was instructed to exercise at maximum strength throughout the ROM. Each exercise involved an extension movement (concentric phase), and another backward or flexion movement, (eccentric phase). 
The execution protocol was performed in isokinetic mode consisting of 3 repetitions (a repetition being extension and flexion) at four constant speeds $(0.15,0.30$, 0.45 and $0.60 \mathrm{~m} \mathrm{x} \mathrm{s}^{-1}$ ). These speeds were selected to facilitate analysis of how work and isokinetic strength peaks varied in an incremental protocol. The recovery between sets (velocity) was 1 minute for both legs. In both protocols participants had a total of 10 minutes of recovery. The mean of 3 repetitions of each strength test was used for data analysis to attempt to eliminate the effects of learning (first series) and fatigue (last series).

The HET was performed using two different grips. For the proximal grip test, the strap was placed just above the kneecap enveloping the entire leg. In the distal grip test, webbing was placed on the ankle, just above the malleoli (Figure 1).

\section{Devices}

To assess strength, an isokinetic device was used (Haefni Health System, Ivolution R\&D, Granada, Spain). The system is designed to test physical activities simulating real life physical motions, be it those of daily movement, or those of an elite athlete. Varying velocities and resistance levels from the electronic motor system take into account participant response and store settings for later use and application in therapy or training sessions.

\section{Statistical analysis}

All results were expressed as mean and standard deviations (SD). An analysis of variance for repeated measures (RM ANOVA) was performed (Day [2] x Protocol [2] x Orientation [2] x Velocity [4]) for each of the dependent variables (PF and W). Reliability analyses were conducted using the formula Index of intraclass correlation (ICC 2,1). To calculate the effect size ( $\eta 2$ ) was used omega ( $\omega 2)$ as the sample size was less than $\mathrm{n}=30$. The Standard Error of Measurement (SEM) was estimated using the formula: $\mathrm{SEM}=\sqrt{\mathrm{MSe}}$, where MSe is the mean square of the errors of the ANOVA [12, 25]. SPSS (version 20 for mac, SPSS Inc, Chicago, IL) was used for analysis.

\section{Results}

Table 1 - Descriptive statistics (mean \pm SD) of the Peak Force variable (PF) during day 2 evaluations

\begin{tabular}{|c|c|c|c|c|}
\hline & \multicolumn{2}{|c|}{ Protocol 1 (Ankle) } & \multicolumn{2}{|c|}{ Protocol 2 (Knee) } \\
\hline & $\begin{array}{c}\text { PF } \\
\text { extension } \\
\text { (N) }\end{array}$ & $\begin{array}{c}\text { PF } \\
\text { flexion } \\
(\mathrm{N})\end{array}$ & $\begin{array}{c}\text { PF } \\
\text { extension } \\
\text { (N) }\end{array}$ & $\begin{array}{l}\text { PF flexion } \\
\text { (N) }\end{array}$ \\
\hline $\begin{array}{c}\text { Velocity } 1 \\
(0.15 \text { m x s-1) }\end{array}$ & $164(48)$ & $201(50)$ & $229(84)$ & $249(73)$ \\
\hline $\begin{array}{c}\text { Velocity } 2 \\
(0.30 \mathrm{~m} \times \mathrm{s}-1)\end{array}$ & $170(41)$ & 237 (51) & $244(98)$ & $291(90)$ \\
\hline $\begin{array}{c}\text { Velocity } 3 \\
(0.45 \mathrm{~m} \times \mathrm{s}-1)\end{array}$ & $165(37)$ & $242(51)$ & $227(84)$ & 307 (94) \\
\hline $\begin{array}{c}\text { Velocity } 4 \\
(0.60 \text { m x s-1) }\end{array}$ & 167 (54) & $250(55)$ & $226(105)$ & $322(104)$ \\
\hline
\end{tabular}

Note: $\mathrm{N}=$ Newton, $\mathrm{PF}=$ Peak Force.

Table 2 - Descriptive statistics (mean \pm SD) of the Work variable $(\mathrm{W})$ during day 2 evaluations

\begin{tabular}{|c|c|c|c|c|}
\hline & \multicolumn{2}{|c|}{ Protocol 1 (Ankle) } & \multicolumn{2}{|c|}{ Protocol 2 (Knee) } \\
\hline & $\begin{array}{c}\text { Work } \\
\text { extension } \\
\text { (N) }\end{array}$ & $\begin{array}{c}\text { Work } \\
\text { flexion } \\
(\mathrm{N}) \\
\end{array}$ & $\begin{array}{c}\text { Work } \\
\text { extension } \\
\text { (N) }\end{array}$ & $\begin{array}{c}\text { Work } \\
\text { flexion } \\
(\mathrm{N})\end{array}$ \\
\hline $\begin{array}{c}\text { Velocity } 1 \\
(0.15 \text { m x s-1) }\end{array}$ & $91(21)$ & $53(12)$ & $101(20)$ & $60(12)$ \\
\hline $\begin{array}{c}\text { Velocity } 2 \\
(0.30 \mathrm{~m} \times \mathrm{s}-1)\end{array}$ & $95(22)$ & $60(15)$ & $109(20)$ & $67(16)$ \\
\hline $\begin{array}{c}\text { Velocity } 3 \\
(0.45 \mathrm{~m} \times \mathrm{s}-1)\end{array}$ & $95(25)$ & $62(17)$ & $110(25)$ & $73(17)$ \\
\hline $\begin{array}{c}\text { Velocity } 4 \\
(0.60 \mathrm{~m} \times \mathrm{s}-1)\end{array}$ & $96(24)$ & $64(16)$ & $111(32)$ & $77(20)$ \\
\hline
\end{tabular}

- Analysis of Peak Force Variable

The RM ANOVA showed significant differences in the protocol effect $\left(F[1,19]=16.174, \rho=0.001, \omega^{2}\right.$ $=0.519,1-\beta=0.964$ ) in the variable PF. The average value of $\mathrm{PF}$ in relation to the protocol, regardless of the other variables was $203 \pm 10.29 \pm 16.57 \mathrm{~N}$ and $251 \mathrm{~N}$ for Protocols 1 (Ankle) and 2 (Knee), respectively.

The RM ANOVA showed significant differences in the interaction day $\times$ protocol $(\mathrm{F}[1,19]=11.780, \rho=$ $\left.0.004, \omega^{2}=0.440,1-\beta=0.894\right)$. The post-hoc Bonferroni showed significant differences $(\mathrm{p}=0.001$ and $\mathrm{p}=0.003)$ for Protocol 1 (Ankle) vs. Protocol 2 (Knee) on days 1 and 2, respectively. The mean values of PF were higher in Protocol 2 (Knee) 262 N vs. $199 \mathrm{~N}$ and $240 \mathrm{~N}$ vs. 207 $\mathrm{N}$, for days 1 and 2, respectively. 
- Analysis of the Work variable

The RM ANOVA showed significant differences in the protocol effect $\left(\mathrm{F}[1,19]=18.154, \rho=0.001, \omega^{2}=0.548\right.$, $1-\beta=0.978$ ) in the variable Work. The average value of Work in relation to the evaluation protocol, regardless of the other variables was $76 \pm 3.60$ and $92 \pm 5.44 \mathrm{~J}$ for Protocol 1 (Ankle) and Protocol 2 (Knee), respectively.

The RM ANOVA showed significant differences in the interaction day $x$ protocol $(\mathrm{F}[1,19]=7.752, \rho=$ $\left.0.014, \omega^{2}=0.341,1-\beta=0.74\right)$. The post-hoc Bonferroni showed significant differences $(\mathrm{p}=0.001$ and $\mathrm{p}=0.001)$ for Protocol 1 (Ankle) vs. Protocol 2 (Knee) on Days 1 and 2 , respectively. The mean values were higher in the Work Protocol 2 (Knee) $95 \pm 6.89$ vs. $75 \pm 3.54$ J for day 1 and $88 \pm 4.92$ vs. $76 \pm 3.54 \mathrm{~J}$ for Day 2 .

Comparison Day 1 vs. Day 2 for Protocol 1 vs.

Protocol 2

-Analysis of the Peak Force Variable

The RM ANOVA showed no significant differences based on Day $\left(F[1,19]=0.462, \rho=0.507, \omega^{2}=0.030\right.$, $1-\beta=0.098$ ) in the variable PF. The average value of $\mathrm{PF}$ according to assessment protocols 1 and 2, regardless of the other variables was $199 \mathrm{~N} \pm 9.16,20.16 \pm 206 \mathrm{~N}$ and $262 \mathrm{~N} \pm 20,240 \pm 15.52 \mathrm{~N}$ for Days 1 and 2, respectively.

The RM ANOVA showed no significant differences in the Protocol $x$ Day interaction $(p=0.475$ and $p=0.125$ ) for the comparison of Protocols 1 (Ankle) and 2 (knee) on Day 1 vs. Day 2, respectively.

\section{- Analysis of the Work Variable}

The RM ANOVA showed no significant differences in the Day effect $\left(F[1,19]=0.462, \rho=0.502, \omega^{2}=0.031\right.$, $1-\beta=0.099$ ) in the Work variable. The average value for Work based on the assessment day regardless of the other variables was $85 \pm 4.88$ and $83 \pm 4.5$ J for Days 1 and 2 , respectively.

The RM ANOVA showed no significant differences in Protocol $x$ Day interaction ( $p=0.680$ and $p=0.191$ ) in comparison of Protocols 1 (Ankle) and 2 (knee) on Day 1 vs. Day 2, respectively.

- Analysis of the Reliability of Protocol 1 (Distal Grip-Ankle)

Table 3 - Summarizes the ICC of Protocol 1 (Distal Grip - Ankle) in all test conditions

\begin{tabular}{cccccccc}
\hline Day 1 & Day 2 & Direction & Variable & $\begin{array}{c}\text { ICC, (SEM [N]) } \\
\text { Velocity 1 }\end{array}$ & $\begin{array}{c}\text { ICC (SEM, [N]) } \\
\text { Velocity 2 }\end{array}$ & $\begin{array}{c}\text { ICC (SEM, [N]) } \\
\text { Velocity 3 }\end{array}$ & $\begin{array}{c}\text { ICC (SEM, [N]) } \\
\text { Velocity 4 }\end{array}$ \\
\hline Protocol 1 & Protocol 1 & 1 & PF & $0.55(53)$ & $0.33(72)$ & $0.65(50)$ & $0.63(62)$ \\
Protocol 1 & Protocol 1 & 2 & PF & $0.59(49)$ & $0.71(55)$ & $0.74(57)$ & $0.74(60)$ \\
Protocol 1 & Protocol 1 & 1 & W & $0.71(16)$ & $0.72(20)$ & $0.78(17)$ & $0.83(20)$ \\
Protocol 1 & Protocol 1 & 2 & W & $0.58(11)$ & $0.59(15)$ & $0.72(13)$ & $0.87(12)$ \\
\hline
\end{tabular}

Note: N: Newton; ICC = Index of intraclass correlation; SEM=Standard Error of Measurement; Velocity Direction $1=$ extension; Velocity Direction 2 = flexion.

Reliability Analysis of Protocol 2 (Proximal Grip Knee)

Table 4 - Summarizes the ICC Protocol 2 (Proximal Grip Knee) for all conditions tested

\begin{tabular}{|c|c|c|c|c|c|c|c|}
\hline Day 1 & Day 2 & Direction & Variable & $\begin{array}{l}\text { ICC (SEM [N]) } \\
\text { Velocity } 1\end{array}$ & $\begin{array}{l}\text { ICC (SEM [N]) } \\
\text { Velocity } 2\end{array}$ & $\begin{array}{l}\text { ICC (SEM [N]) } \\
\text { Velocity } 3\end{array}$ & $\begin{array}{l}\text { ICC (SEM [N]) } \\
\text { Velocity } 4\end{array}$ \\
\hline Protocol 2 & Protocol 2 & 1 & PF & $0.52(41)$ & $0.38(56)$ & $0.55(43)$ & $0.76(49)$ \\
\hline Protocol 2 & Protocol 2 & 2 & PF & $0.56(40)$ & $0.69(40)$ & $0.63(50)$ & $0.68(45)$ \\
\hline Protocol 2 & Protocol 2 & 1 & W & $0.56(15)$ & $0.76(12)$ & $0.83(12)$ & $0.82(12)$ \\
\hline Protocol 2 & Protocol 2 & 2 & W & $0.57(11)$ & $0.72(9)$ & 0.68 (10) & $0.79(9)$ \\
\hline
\end{tabular}




\section{Discussion}

One of the main objectives of this study was to analyze which protocol (distal grip-ankle vs. proximal grip-knee) performed on an isokinetic device best represented the action of a hip extension (concentriceccentric phase) carried out from a functional position. In addition, another objective was to analyze the test - retest reliability of the variables PF and W in both evaluation protocols.

The main contribution of this research is the novelty of a hip extension protocol from a standing position. Most papers found in the literature on the subject (5, 17, 20, 24 - 26) have evaluated the performance of hip extension from a supine position. In our point of view, evaluation of the hip extension from a lying-down position does not represent a biomechanical reality regarding the use of hip muscles. This is, at best, an isolated and analytical evaluation, since it does not take into account the stabilizing role of the hip in addition to the involvement of different muscle chains. Furthermore, some other research $(9,27)$ assessed this exercise starting from a standing position. Similarly, our research is based on a standing position, in addition to the use of a stabilizer to ensure an upright position of the torso (Figure 1). The HHe1.0 device enabled the maximum dynamic force of the hip extensor muscles to be measured isokinetically with a linear force vector for the first time (28). From a purely muscular point of view, of the action generated in Protocol 2 (proximal grip knee) resulted in higher values of PF and W (Table 1), in both the concentric and eccentric phase. One possible explanation is that the realization of this protocol does not interfere with other muscles and levers not being evaluated. It allows the sole evaluation of the hip extensor muscles. Moreover, in evaluation from a functional, or standing position, the synergistic muscles, or hip stabilizer muscles execute a firmer position. However, the main problem in the implementation of Protocol 1 (distal grip-ankle) was maintaining standardization of the angle of the knee joint, which increases the variability in the standardization of movement. However, it is worth noting that there were no significant differences found in the comparison of protocol 1 on both evaluation days.

In the analysis of the test-retest reliability PF and $\mathrm{W}$ variables (see Table 3 and 4), the results showed little to moderate reliability. Performing a detailed analysis, except for the velocity of $0.30 \mathrm{~m} \mathrm{x} \mathrm{s}^{-1}$, the reliability analysis, analyzed using ICC, varies between 0.52 and 0.83 , that is, moderate to good reliability. On the other hand, the SEM obtained for both variables in all evaluation conditions shows a low measurement error. This indicates that although reliability from the ICC was moderate, and even low in some conditions, the SEM was low, indicating good reliability for the measures of PF and W in both assessment protocols. Notably, no significant differences $(\mathrm{p}=0.475, \mathrm{p}=0.125$ and $\mathrm{p}=$ $0.680, p=0.191$ ) either for the PF variable, nor $W$ were found in the interaction protocol $\mathrm{x}$ day, for protocols 1 and 2 , respectively. This, together with the reliability analysis, indicates the hip extension exercise in concentric/eccentric phases is stable after multiple consecutive measurements. Studies like those by Claiborne et al. (27) also evaluated the strength of hip extension in a standing position with a straight trunk. In this case, the hip was locked in a stable position using belts to immobilize the pelvis during each repetition. ICC values for the extension were 0.90 and 0.76 (concentric and eccentric phase) for the right leg and 0.80 for the left leg, both in the concentric and eccentric phase. ICC values for hip flexion were $0.83,0.90$ and $0.82,0.74$, in the concentric and eccentric phases for the right and left legs respectively. Burnett et al. (23) were one of the first to evaluate the strength of the hip extensor muscles in children with isokinetic dynamometry with an ICC of 0.68 and 0.84 at $30^{\circ} \mathrm{x} \mathrm{sec}^{-1}$ and $90^{\circ} \mathrm{x} \mathrm{sec}^{-1}$, respectively. Nadler et al. (25) obtained reliability of 0.94 to 0.98 with a portable dynamometer, with a CV less than 9\%. This procedure has been used in other studies, such as that of Pua et al. (29) which evaluated the hip extension in the same position (ICC $=0.84$ to 0.97). In all these studies the evaluation position of the flexion/extension of the hip had the subject lying supine, concluding that the force can be evaluated with good to very good reliability. As already mentioned, in contrast to all the above studies $(9,27,30)$ in our research the hip extension exercise was evaluated starting from an anatomical position. The main advantage of this condition is its similarity to the force exerted as compared to a real situation. On the other hand, when performing this type of evaluation from a standing position, care must be taken to standardize the evaluation movement since the slightest change in position can lead to distortions in measurement. The main obstacles to reliability of the evaluation protocol are (a) standardization of the initial and final position and movement using a goniometer; (b) familiarization with the movement to be evaluated, regardless of the length of the segment rating all assessments must be conducted at the same angle; (c) controlling the handgrip during the execution of the 
movement as excessive force transmitted through arm - trunk complex can distort the results; and finally (d) monitoring by the same researcher while the continuous assessment (eccentric-concentric phase) protocol is carried-out. Additionally, the subject must be very concentrated during the performance of each of the repetitions to ensure reliable results.

From a kinetic and kinematic view, the results presented in this paper support the proximal grip selection in Protocol 2 for the evaluation of the hip extension exercise. Further research including electromyography devices is needed to analyze recruitment patterns of all lower body muscles, both in the main action of hip extension, and the stabilization of the position by the synergist muscles. This information may be relevant in predicting deficits of neuromuscular coordination (with its consequent high potential to suffer from certain conditions) that activate both inappropriate corrective mechanisms in the lower back muscles and lower body.

\section{Conclusions}

The results indicate, first, that the protocol that best represents the action of hip extension without involving other muscles involved in the action of hip extension is Protocol 2 (proximal grip knee). Furthermore, the analysis of the test-retest reliability evaluation of both protocols showed that both the PF and $\mathrm{W}$ variables are more stable during Protocol 2 (proximal grip knee.) Finally, the importance of good procedure to standardize assessment positions to avoid adverse negative effects during data collection must be emphasized.

\section{Limitations}

A major limitation of this study was restrictive ROM set at $30 \mathrm{~cm}$ for all participants, regardless of the length of their lower body segments, in order to evaluate the $\mathrm{W}$ variable.

\section{Acknowledgements}

We would like to thank Rafael Ortega, Director, Fisiosalud (Hazard, Granada, Spain) for making his clinic available and loaning his facilities to collect the data for this study.

\section{References}

1. Hortobagyi T, Rider P, Gruber AH, DeVita P. Age and muscle strength mediate the age-related biomechanical plasticity of gait. Eur J Appl Physiol. 2016;116(4):805-14.

2. Luedke LE, Heiderscheit BC, Williams DS, Rauh MJ. Association of isometric strength of hip and knee muscles with injury risk in high school cross country runners. Int J Sports Phys Ther. 2015;10(6):868-76.

3. Nankaku M, Ikeguchi R, Goto K, So K, Kuroda Y, Matsuda S. Hip external rotator exercise contributes to improving physical functions in the early stage after total hip arthroplasty using an anterolateral approach: a randomized controlled trial. Disabil Rehabil. 2016:1-6.

4. Horsak B, Artner D, Baca A, Pobatschnig B, GreberPlatzer S, Nehrer S, et al. The effects of a strength and neuromuscular exercise programme for the lower extremity on knee load, pain and function in obese children and adolescents: study protocol for a randomised controlled trial. Trials. 2015;16:586.

5. Bera SG, Brown LE, Zinder SM, Noffal GJ, Murray DP, Garrett NM. The effects of velocity-spectrum training on the ability to rapidly step. J Strength Cond Res. 2007;21(4):1101-7.

6. Claiborne TL, Armstrong CW, Gandhi V, Pincivero DM. Relationship between hip and knee strength and knee valgus during a single leg squat. J Appl Biomech. 2006;22(1):41-50.

7. Hopkins WG. Measures of reliability in sports medicine and science. Sports Med. 2000;30(1):1-15.

8. Kannus P. Isokinetic evaluation of muscular performance: implications for muscle testing and rehabilitation. Int J Sports Med. 1994;15 (Suppl 1):S11-8.

9. Kollock Jr RO, Van Lunen B, Linza JL, Onate JA. Comparison of Isometric Portable Fixed Dynamometry to Isokinetic Dynamometry for Assessment of Hip Strength. IJATT. 2013;18(6):1-6.

10. Pereira MIR, Gomes PSC. Movement velocity in resistance training. Sports Med. 2003;33(6):427-38.

11. Hollman JH, Kolbeck KE, Hitchcock JL, Koverman JW, Krause DA. Correlations Between Hip Strength and Static Foot and Knee Posture. J Sport Rehab. 2006;15(1):12-23.

12. Friel K, McLean N, Myers C, Caceres M. Ipsilateral hip abductor weakness after inversion ankle sprain. J Athl Train. 2006;41(1):74-8. 
13. Powers CM. The influence of altered lower-extremity kinematics on patellofemoral joint dysfunction: a theoretical perspective. J Orthop Sports Phys Ther. 2003;33(11):639-46.

14. Hewett TE, Myer GD, Ford KR. Anterior cruciate ligament injuries in female athletes: Part 1, mechanisms and risk factors. Am J Sports Med. 2006;34(2):299-311.

15. Cichanowski HR, SchmittJS, Johnson RJ, Niemuth PE. Hip strength in collegiate female athletes with patellofemoral pain. Med Sci Sports Exerc. 2007;39(8):1227-32.

16. Kang SY, Jeon HS, Kwon O, Cynn HS, Choi B. Activation of the gluteus maximus and hamstring muscles during prone hip extension with knee flexion in three hip abduction positions. Man Ther. 2013;18(4):303-7.

17. Boling MC, Padua DA, Creighton RA. Concentric and eccentric torque of the hip musculature in individuals with and without patellofemoral pain. J Athl Train. 2009;44(1):7-13.

18. Silva RS, Veronese LM, Granado Ferreira AL, Serrao FV. The influence of forefoot varus on eccentric hip torque in adolescents. Man Ther. 2013;18(6):487-91.

19. Erdemir A, McLean S, Herzog W, van den BogertAJ. Modelbased estimation of muscle forces exerted during movements. Clin Biomech (Bristol, Avon). 2007;22(2):131-54.

20. Ruckert E, d'Avella A. Learned parametrized dynamic movement primitives with shared synergies for controlling robotic and musculoskeletal systems. Front Comput Neurosci. 2013;7:138.

21. Van den Bogert AJ, Geijtenbeek T, Even-Zohar O, Steenbrink F, Hardin EC. A real-time system for biomechanical analysis of human movement and muscle function. Med Biol Eng Comput. 2013;51(10):1069-77.

22. Weir JP. Quantifying test-retest reliability using the intraclass correlation coefficient and the SEM. J Strength Cond Res. 2005;19(1):231-40.

23. Burnett CN, Betts EF, King WM. Reliability of isokinetic measurements of hip muscle torque in young boys. Phys Ther. 1990;70(4):244-9.

24. Baldon Rde M, Lobato DF, Carvalho LP, Santiago PR, Benze BG, Serrao FV. Relationship between eccentric hip torque and lower-limb kinematics: gender differences. J Appl Biomech. 2011;27(3):223-32.
25. Nadler SF, DePrince ML, Hauesien N, Malanga GA, Stitik TP, Price E. Portable dynamometer anchoring station for measuring strength of the hip extensors and abductors. Arch Phys Med Rehabil. 2000;81(8):1072-6.

26. Tourville TW, Smith HC, Shultz SJ, Vacek PM, Slauterbeck JR, Johnson RJ et al. Reliability of a new stabilized dynamometer system for the evaluation of hip strength. Sports Health. 2013;5(2):129-36.

27. Claiborne TL, Timmons MK, Pincivero DM. Test-retest reliability of cardinal plane isokinetic hip torque and EMG. J Electromyogr Kinesiol. 2009;19(5):e345-52.

28. Jara CAC, González IJB, Ríos IJC, Tamayo IM, Fuenzalida AEL, Ríos IJC. Validación y fiabilidad del dispositivo Haefni Health System 1.0 en la medición de la velocidad en el rango isocinético. Cuadernos de Psicología del Deporte. 2014;14(2):91-8.

29. Pua YH, Wrigley TV, Cowan SM, Bennell KL. Intrarater test-retest reliability of hip range of motion and hip muscle strength measurements in persons with hip osteoarthritis. Arch Phys Med Rehabil. 2008;89(6):1146-54.

30. Sakamoto AC, Teixeira-Salmela LF, Paula-Goulart FR, Faria CDM, Guimaraes CQ. Muscular activation patterns during active prone hip extension exercises. J Electromyogr Kinesiol. 2009;19(1):105-12.

Received in 11/27/2015

Recebido em 27/11/2015

Approved in 05/12/2016 Aprovado em 12/05/2016 